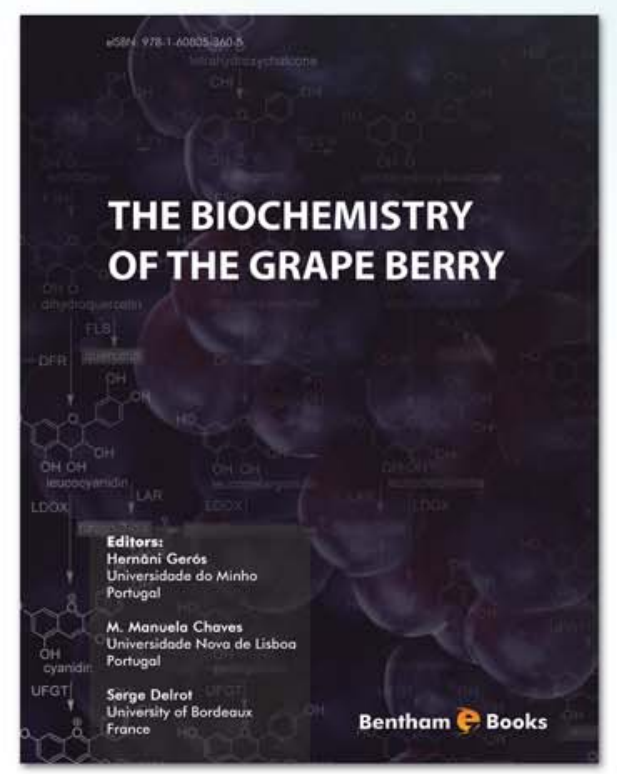

\section{Editors:}

Hernâni Gerós

Minho

Manuela Chaves

Portugal

Serge Delrot

France

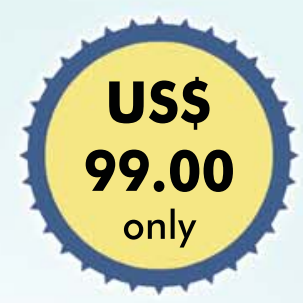

elSBN: 978-1-60805-360-5

\title{
The Biochemistry of the Grape Berry
}

\section{Wwwhenthamseience.com/ebooks/9781608053605}

\section{About the ebook}

This e-book is a pioneer offering for readers - giving a focused and integrated coverage of the key biochemical and molecular aspects of grape berry development and ripening. The comprehensive range of topics covered in this e-book is valuable to a multidisciplinary readership including plant physiologists, enologists, microbiologists, wine makers, biochemists and students.

\section{Contents}

- Water Relations of the Grape Berry and Aquaporins

- Mineral Compounds in the Grape Berry

- Source/Sink Relationships and Molecular Biology of Sugar Accumulation in Grape Berries

(-) The Biochemistry of Organic Acids in the Grape

- Phenolics in Grape Berry and Key Antioxidants

- Aroma and Aroma Precursors in Grape Berry

- Polyamines and Grape Berry Development

- Grape Cell Vacuoles: Structure-Function and Solute Transport Across the Tonoplast

For Advertising Inquiries: Contact: marketing@benthamscience.org 